practically, insulin dependent diabetics) in a single jail near to a well staffed diabetic clinic. The extra workload would require extra NHS resources. The basic concept of this type of care is not new; the Wormwood Scrubs Annexe has been operating successfully for some time and caters solely for prisoners who have committed sex offences or have drug or alcohol problems. Among diabetic prisoners, however, manipulative behaviour might escalate to disastrous proportions. In addition, visiting by relatives and provision of varying degrees of security would be difficult with this type of single prison.

A compromise solution, which is potentially achievable, is to place diabetic prisoners treated with insulin in selected jails close to large, active diabetic clinics, to which these prisoners could be taken for routine care. For type II diabetes a simple programme of organisation and education for prison medical officers should facilitate adequate care for patients without recourse to the diabetic clinic unless problems arise. This system would be analogous to programmes of diabetic care based in general practice, which are now being widely developed in the United Kingdom.
We have discussed these options with local and national prison medical authorities and hope that some form of structured care for imprisoned diabetic patients will result. Changes to the present system require careful thought and consideration, and discussion on these issues is welcome.

We thank Dr John Kilgour, director of the prison medical service, and Dr Andrew Todd, principal medical officer at Walton Jail for discussion and cooperation and Mrs Hazel Jenkins for excellent secretarial help.

I Smith R. Prison health care. London: British Medical Association, 1984. Prison Reform Trust. Prison medicine. London: Prison Reform Trust, 1985. 3 Anonymous. The future of the prison medical service [Editorial]. Lancet 1985;ii:755-6.

4 Burrin JM, Newton-Adair I, Fyffe JA. Performance of the Reflocheck system used outside the laboratory by trained non-laboratory personnel. Practical Diabetes 1987;4:167-8.

5 Gill GV, Husband DJ, Walford S, Marshall SM, Home PD, Alberti KGMM Clinical features of brittle diabetes. In: Pickup JC, ed. Brittle diabetes. London: Blackwell, 1985:29-40.

6 Home P, Walford S. Diabetes care: whose responsibility? Br Med f 1984;289: 713-4.

(Accepted 11 November 1988)

列

\title{
Counselling in a general practice setting: controlled study of health visitor intervention in treatment of postnatal depression
}

\author{
Jenifer M Holden, Ruth Sagovsky, John L Cox
}

\begin{abstract}
Objective-To determine whether counselling by health visitors is helpful in managing postnatal depression.

Design-Controlled, random order trial.

Setting - Health centres in Edinburgh and Livingston.

Patients - Sixty women identified as depressed by screening at six weeks post partum and by psychiatric interview at about 13 weeks post partum. Five women did not wish to participate, and a further five did not complete the trial. Age, social and obstetric factors, and diagnosis were similar in women who completed the trial and those who withdrew.
\end{abstract}

Intervention-Eight weekly counselling visits by health visitors who had been given a short training in counselling for postnatal depression.

End point-Reduction of depression.

Measurements and main results-Standardised psychiatric interviews and a 10 point self report scale were used to identify depression before and after intervention. The psychiatrist was not told to which group women were allocated. After three months $18(69 \%)$ of the 26 women in the treatment group had fully recovered compared with nine $(38 \%)$ of the 24 in the control group. The difference between the groups was thus $32 \%$ (95\% confidence interval 5 to 58).

Conclusions-Counselling by health visitors is valuable in managing non-psychotic postnatal depression.

\section{Introduction}

Postnatal depression affects $12-15 \%$ of mothers and may mark the onset of long standing psychiatric disorder. ${ }^{1.3}$ Maternal depression has been found to have adverse effects on the behavioural, intellectual, and emotional development of children, ${ }^{47}$ and general practitioners have shown the importance of postnatal depression in primary care.$^{89}$ The role of psychosocial factors in the aetiology of postnatal depression has been clearly demonstrated, ${ }^{1-3}$ and research findings support the view that "therapeutic listening" and extra support may be particularly helpful in depression occurring at this time. Snaith pointed out that what most women with depression after childbirth need is extra support and someone to listen. ${ }^{10}$ Similar observations were made by Kumar and Robson, ${ }^{2}$ Elliott, ${ }^{11}$ and Cox. ${ }^{12}$ Cutrona and Troutman showed that social support protects against postnatal depression, ${ }^{13}$ and Barnett and Parker found that anxiety in first time mothers can be reduced by professional support. ${ }^{14}$ Solom and Bromet assessing the vulnerability model of Brown and Harris ${ }^{15}$ suggested that lack of a confiding relationship may be an important area for intervention in the treatment of depressive disorder. ${ }^{16}$

Corney found that health visitors can help alleviate depression by visiting clients frequently and encouraging the expression of feelings. ${ }^{17}$ Hennessy, however, found that health visitors had recognised only $27 \%$ of mothers she identified as depressed, ${ }^{18}$ and Briscoe and Williams observed that health visitors should be given opportunities to develop their counselling skills. ${ }^{19} \mathrm{We}$ therefore decided to carry out a randomised controlled trial to determine the effectiveness of counselling by health visitors given a brief training in the management of postnatal depression.

\section{Subjects and methods}

THE HEALTH VISITORS

All the 17 health visitors working in three health centres in Edinburgh and two in Livingston agreed to take part in the trial, with the support of general practitioners and nursing management. The health visitors were a well qualified group in terms of professional and life experience. They had worked as health visitors for a mean of 6.8 years (range 2-12), and, 
apart from their general nursing and health visitor qualification, three had university degrees, twelve were midwives, two had psychiatric training, and two had teaching experience. All were women, and their mean age was $40 ; 13$ were married, and seven had children. All worked full time and were attached to general practices.

\section{TRAINING THE HEALTH VISITORS}

Our teaching programme was based on Rogerian or non-directive counselling methods. The major assumption of this approach is that talking about their feelings to an empathic and non-judgmental professional will help people to take a more positive view of themselves and their lives. Our training emphasised the importance of listening to clients and encouraging them to make decisions based on their own judgment rather than giving advice. Each health visitor was given a manual describing postnatal depression and nondirective counselling prepared by $\mathrm{JMH}^{20}$ and attended three weekly training sessions of two hours. A small group size (three to four in each centre) encouraged individual participation and discussion. The course included instruction in counselling methods such as non-verbal encouragement and reflecting back the content of what has been said, but it was emphasised that a confiding relationship is more important than specific techniques. ${ }^{21}$

Three videotapes were used to illustrate the relevance of counselling in postnatal depression. In the first recovered mothers described their experience and expressed their need for the opportunity to talk about their feelings. The second videotape highlighted possible conflicts between the counselling role and the mother's expectation that the health visitor will provide specific advice. The third videotape, showing a counsellor with a tearful mother, was designed to provoke discussion of the counsellor's own feelings. The health visitors also played the part of counsellor and client and were encouraged to practise counselling with clients in their case load.

\section{THE INTERVENTION}

The health visitors were asked to visit women in the treatment group at a prearranged time for eight successive weeks. At least half an hour was to be spent counselling, infant care being discussed separately. The health visitors were not informed of women in the control group, and we emphasised that the counselling should be offered only to women referred by the researchers. The doctors were informed of any of their patients included in the study but were not told to which group the women had been assigned.

\section{METHODS OF ASSESSMENT}

Depression was assessed by the psychiatrist (RS) before and after the intervention using three standardised measures.

Goldberg's standardised psychiatric interview ${ }^{22}-$ This semistructured interview includes a four point rating for 10 psychiatric symptoms and 12 manifest abnormalities of the mental state, including the interviewer's clinical rating of the subject's mood as observed during the interview (observed depression). The total score is the sum of the 10 symptom ratings added to twice the ratings of manifest abnormalities. The interview was modified to allow the research diagnostic criteria of Spitzer $e t a l^{23}$ to be applied and to take into account somatic symptoms normal to the postnatal period - for example, fatigue or sleep disturbance due to a wakeful baby. RS was trained in the use of the interview, and depression ratings were discussed with JLC.

The Edinburgh postnatal depression scale-This self report scale consists of 10 statements, each with four possible responses relating to depressive symptoms, rated $0-3$. The mother was asked to underline the response that most closely reflected her feelings during the previous week, and the total score was a sum of the scores for each item. The scale has been shown to have satisfactory validity and reliability and to be sensitive to changes in the severity of depression over time. ${ }^{24}$

Statistical methods-The changes in the mean total standardised psychiatric interview scores, the standardised psychiatric interview observed depression subscores, and the mean Edinburgh postnatal depression scale scores at the first and second psychiatric interview were tested with Wilcoxon's signed rank test. The differences between the two groups in these changes were then tested with a Mann-Whitney rank test for independent samples.

\section{DESIGN OF THE STUDY}

Seven hundred and thirty four women attending child health clinics at the five centres were screened for postnatal depression with the depression scale about six weeks after delivery. Those who scored above the threshold of $12 / 13$ were interviewed at home by the psychiatrist RS about 12 weeks after delivery with the psychiatric interview, and a second depression scale was completed. Sixty women were found to be depressed according to research diagnostic criteria, and the 55 who agreed to participate were allocated using random numbers to the treatment or control group. (The number of women found to be depressed was not an indication of the rate of postnatal depression among our initial screening sample. Some women who had scored high on the depression scale at six weeks were no longer depressed 12 weeks after delivery, some high scorers were not available for interview, and some women who scored below threshold at six weeks may have become depressed later.) Fifty women completed the trial, 26 in the treatment group and 24 in the control group.

After a mean time interval of 13 weeks, during which women in the treatment group had received a mean of 8.8 weekly counselling visits from their health visitor, the interview and the depression scale were again administered at home to both groups of women by the psychiatrist RS, who did not know to which group the mother had been allocated. Women were considered as having recovered only when they no longer fulfilled research diagnostic criteria for major or minor depressive illness

\section{THE SAMPLE}

Table I shows the details of the 50 women in the study. The mean age of the mothers was 26 years and that of their babies 13 weeks at the first interview. Nine mothers were delivered by caesarean section, and five had a forceps delivery. Forty seven had permanent partners and three were single. According to their partner's occupation, $12 \%$ of the sample were from social classes I and II, $40 \%$ from social class III, and

TABLE I-Distribution of social and obstetric factors. Results are numbers (and percentages)

\begin{tabular}{lccc}
\hline & $\begin{array}{c}\text { Counselled } \\
(\mathbf{n}=26)\end{array}$ & $\begin{array}{c}\text { Control } \\
(\mathbf{n}=24)\end{array}$ & $\begin{array}{c}\text { Total } \\
(\mathbf{n}=50)\end{array}$ \\
\hline Mean age (years) & $27 \cdot 6$ & $24 \cdot 6$ & $26 \cdot 2$ \\
Parity: & $8(30)$ & $6(25)$ & $14(28)$ \\
$\quad$ Primiparous & $18(70)$ & $18(75)$ & $36(72)$ \\
$\quad$ Multiparous & $2 \cdot 4$ & $2 \cdot 3$ & $2 \cdot 4$ \\
$\quad$ Mean number of pregnancies & $15(58)$ & $21(87)$ & $36(72)$ \\
Type of delivery: & $5(19)$ & & $5(10)$ \\
$\quad$ Spontaneous vertex & $6(23)$ & $3(13)$ & $9(18)$ \\
$\quad$ Forceps delivery & & & \\
$\quad$ Caesarean section & $3(11)$ & $3(12)$ & $6(12)$ \\
Social class: & $11(41)$ & $9(38)$ & $20(40)$ \\
$\quad$ I and II & $13(48)$ & $12(50)$ & $24(48)$ \\
$\quad$ III & $10(38)$ & $11(45)$ & $21(42)$ \\
$\quad$ IV and V & $17(65)$ & $17(71)$ & $34(68)$ \\
Previous depression & & & \\
Major depression at first interview & & & \\
& & &
\end{tabular}


TABLE II - Changes in measures of depression over study period

\begin{tabular}{|c|c|c|c|c|c|c|c|c|}
\hline & \multirow[b]{3}{*}{ No } & \multirow{2}{*}{\multicolumn{2}{|c|}{ Median score }} & \multicolumn{3}{|c|}{$\begin{array}{l}\text { Within group changes in median } \\
\text { scores on measures of depression at } \\
\text { diagnostic psychiatric interviews }\end{array}$} & \multicolumn{2}{|c|}{$\begin{array}{l}\text { Significance of } \\
\text { difference in changes } \\
\text { between groups }\end{array}$} \\
\hline & & & & \multirow{2}{*}{$\begin{array}{l}\text { Median } \\
\text { change }\end{array}$} & \multirow{2}{*}{$\begin{array}{l}95 \% \text { Confidence } \\
\text { interval }\end{array}$} & \multirow[b]{2}{*}{$\mathrm{p}^{\star}$} & \multirow{2}{*}{$\begin{array}{l}95 \% \text { Confidence } \\
\text { interval }\end{array}$} & \multirow[b]{2}{*}{$\mathrm{p} \dagger$} \\
\hline & & Time 1 & Time 2 & & & & & \\
\hline \multicolumn{9}{|c|}{ Standardised psychiatric interview (total score) } \\
\hline Counselled & 26 & $25 \cdot 5$ & $14 \cdot 0$ & $-12 \cdot 5$ & -17 to -7 & 0.001 & 7 to -4 & \\
\hline Control & 24 & $24 \cdot 0$ & $23 \cdot 0$ & $-2 \cdot 0$ & -6 to 3 & NS & to -4 & 0.01 \\
\hline \multicolumn{9}{|c|}{ Standardised psychiatric interview (observed depression) } \\
\hline Counselled & 26 & $2 \cdot 0$ & 0.5 & $-2 \cdot 0$ & -2 to -1 & 0.001 & $-2+00$ & $0 \cdot 01$ \\
\hline Control & 24 & $2 \cdot 0$ & $2 \cdot 0$ & & -1 to 0 & NS & -2 to 0 & 0.01 \\
\hline \multicolumn{9}{|c|}{ Edinburgh postnatal depression scale } \\
\hline Counselled & 26 & $16 \cdot 0$ & $10 \cdot 5$ & $-6 \cdot 0$ & -8 to $-4 \cdot 5$ & 0.001 & -7 to -2 & 0.01 \\
\hline Control & 24 & $15 \cdot 5$ & $12 \cdot 0$ & -1.5 & -4 to 0.5 & NS & -7 to -2 & \\
\hline
\end{tabular}

*Wilcoxon's signed rank test.

† Mann-Whitney test for independent samples.

$48 \%$ from social classes IV and V. Social variables, history of depression, and major or minor depressive disorders were similarly distributed between the two groups, though more women in the counselled group had had complications at delivery.

\section{Results}

Our main finding was that, according to research diagnostic criteria, $18(69 \%)$ of the 26 depressed women in the treatment group showed no evidence of having a major or minor depressive illness at the second interview, whereas only nine (38\%) of the 24 women in the control group had recovered. Recovery was not related to type of delivery or to the severity of the depression at the first interview. More counselled mothers with both major and minor depressions recovered than did controls. The difference in recovery rate between the groups was $31 \cdot 7 \%(95 \%$ confidence interval 5 to $\left.58 ; \chi^{2}=5.06 ; \mathrm{df}=1 ; \mathrm{p}=0.03\right)$.

Table II shows the changes in measures of depression at the first and second psychiatric interviews. The counselled women showed a significant $(p<0 \cdot 001)$ reduction in mean scores from the first to the second interview on all measures of depression, whereas the reduction in mean scores of the controls was not significant. The difference between the two groups in the amount of reduction on all measures was significant $(\mathrm{p}<0.01)$.

\section{Discussion}

The results of this study confirmed our hypothesis that health visitors given a brief training in nondirective counselling can help women to recover from postnatal depression and also indicate that depression occurring after childbirth is amenable to "therapeutic listening" and social support. The improved rate of recovery was not due to more counselled mothers taking antidepressants; of the 12 women who were offered antidepressants only three in each group were considered by their doctor to have taken a therapeutic dose. All three counselled women recovered compared with only one of the three in the control group. (This woman had, we later discovered, been counselled by a community psychiatric nurse). Although the numbers were small, these findings suggest that antidepressants given to women at this time are more effective when combined with counselling.

Although previous research has shown that some cases of postnatal depression may remit spontaneously within three months,' our data show that the counselling intervention itself led to the recovery of almost one third of the women in the study. This effect may have been due partly to the social support provided by the health visitors. The origins of depression may be rooted in a lack of adequate nurturing in the woman's own childhood, ${ }^{25}{ }^{26}$ (A T Bifulco, G W Brown, T O Harris, the Islington study manuscript, 1987) and the extra attention may have helped to offset the effects of the unmet need of some women for being mothered themselves. Some justification for this view came from tape recorded follow up interviews conducted by JMH three months after the second diagnostic psychiatric assessments had been made. Nine of the mothers in our study had lost their own mother, of whom three of the five who were in the treatment group recovered compared with only one of the four in the control group. Many of the women who had been in the treatment group described having felt supported and comforted by the weekly visits-for example: "It helped just knowing someone was there... to sort of catch me if I fell." Some women described their health visitor as a friend, one said she was like a big sister, and three said that their health visitor had been like a mother to them.

The therapeutic role of the counselling itself, however, was apparent from the women's descriptions. When asked if they had received any help for their depression, $23(88 \%)$ counselled women claimed that talking to their health visitor had been the most important factor in their recovery. Their belief was convincing - for example, one woman said: "If someone had told me that a professional could come every week and let me talk for half an hour, and that I would end up a healed person, I wouldn't have believed it. It sounds like nonsense, but it's true." The importance of being given "permission to speak" was also described: "I wouldn't have told anyone how I felt unless I'd been asked. I'd been bottling it all up like a schoolgirl, don't speak until you're spoken to. But I could get everything in the open with her, and after a few weeks I really felt I was getting rid of the depression; it was actually coming away from me."

Feelings of guilt are one of the commonest symptoms of depression, and guilt about the depression itself is particularly likely to accompany depression after childbirth as media representations of maternal contentment conflict with the woman's actual experience. "No one tells you about postnatal depression before you have the baby. When it happens you feel guilty, you think it's somehow your fault. You get frightened and think they'll lock you away." Many women said that talking to their health visitor had relieved them from feeling responsible for their depression, and others said that relief from guilt had enabled them to confide in their partner and enlist his support. Three women claimed that their contact with the health visitor had saved their relationship: "Talking to the health visitor saved my marriage, definitely. I had reached the stage where I couldn't have cared less if he had walked out of the door."

Clearly the intervention of the health visitor had a therapeutic effect. One third of the counselled women, however, did not recover despite the intervention. Of this subgroup, two had a long history of depressive illness, another had had postpartum depression before, and a further two had a family history of depressive illness. Postnatal depression occurring in the context of a continuum of psychiatric disturbance may be "biological" in origin, ${ }^{2327}$ and such depression may be less likely to respond to a psychosocial intervention.

Almost a fifth of the total sample appear to have recovered spontaneously. The women who did not receive the intervention may, nevertheless, have benefited from taking part in the study. In a review of 48 studies of psychotherapeutic outcome Bergin and Lambert pointed out that "untreated" clients are often helped by a single interview..$^{28}$ Many women who had been in the control group indicated that it had been a relief to have their depression recognised and said that 
they had appreciated the opportunity to talk about their feelings during the diagnostic interviews.

Women who were still depressed at the second psychiatric interview were advised to seek further help, and a year later the doctors were asked about their progress. Five of the eight counselled women who had not recovered were reported to have consulted their doctors about the depression compared with only two of the 15 women from the control group. Possibly the attention of their health visitor may have encouraged counselled women to view their depression as a legitimate reason to consult, increasing their compliance with respect to further treatment.

When asked about their participation in the study the health visitors commented that much of their time is in any case spent with mothers they suspect of being depressed. The training had provided a structured approach to postnatal depression, which enabled them to use their time more effectively, and, whereas previously the baby had been the main focus of their attention, they were now increasingly oriented towards the psychological well being of the mother. The health visitors also reported that they found the non-directive technique useful with other clients. The study illuminated, however, the need for support for the health visitors. One counselled mother and two from the control group had been referred to a psychiatrist, and several more would have benefited from psychiatric advice being readily available either to the mother or to the primary care workers. The study also showed the need for parents to be given more information before delivery about the realities of parenthood and the possibility of postnatal depression.

Although confidence in the robustness of our findings should be tempered by the relatively small sample size, the superior rate of recovery of depressed women who were counselled by their health visitor compared with those who did not receive counselling has implications for the training of both student and practising health visitors in methods of counselling and in the identification of postnatal depression. Our data suggest that health visitors attached to a general practice may usefully be encouraged to offer a structured programme of counselling to mothers with postnatal depression and that mothers will accept them in this role.

We thank the health visitors and mothers whose active participation made this study possible; the general practitioners and nursing management for their support; Ralph Maguire and Robert Elton for statistical advice; and Richard Bambridge and Marjorie Dodds for their help and interest.
The research was funded by the Scottish Home and Health Department.

1 Cox JL, Connor Y, Kendell RE. Prospective study of the psychiatric disorders of childbirth. Brf Psychiatry 1982;140:111-7.

2 Kumar R, Robson KM. A prospective study of emotional disorders in childbearing women. Br F Psychiatry 1984;144:35-47.

3 Watson JP, Elliott SA, Rugg AJ, Brough DI. Pswchiatric disorder in pregnancy and the first postnatal year. Brf Psychiatry 1984;144:453-62.

4 Ghodsian M, Zajicek E, Wolkind S. A longitudinal study of maternal depression and child behaviour problems. I Child Psychol Psychiatr depression and

5 Richman N, Stevenson J, Graham P. Preschool to school: a behavioural study. London: Academic Press, 1982

6 Cogill SR, Caplan HL, Alexandra H, Robson KM. Impact of maternal depression on the cognitive development of young children. Br Med $f$ 1986;292:1165-7

7 Wrate RM, Rooney AC, Thomas PF, Cox JL. Postnatal depression and child development: a 3-vear follow-up study. Br J Psychiatry 1985;146:622-7.

8 Playfair HR, Gowers JL. Depression following childbirth: a search for predictive signs. I R Coll Gen Pract 1981;31:201-8.

9 Ancill R, Hilton S, Carr T, Tooley M, McKenzie A. Screening for antenatal and postnatal depressive symptoms in general practice using a microcomputer-delivered questionnaire. $f R$ Coll Gen Pract 1986;36:276-9.

10 Snaith RP. Pregnancy-related psychiatric disorder. Br F Hosp Med 1983;29. 450-7.

11 Elliott SA. Pregnancy and after. In: Rachman S, ed. Contributions to medical psychology. Vol 3. Oxford: Pergamon, 1984:93-116.

12 Cox JL. Postnatal depression: a guide for health professionals. Edinburgh: Churchill Livingstone, 1986

13 Cutrona CE, Troutman BR. Social support, infant temperament and parenting self-efficacy: a mediational model of postpartum depression. Child Development 1986;57:1507-18.

14 Barnett B, Parker G. Professional and non-professional intervention for highly anxious primiparous mothers. Br $\mathcal{F}$ Psychiatry 1985;146:287-93.

15 Brown GW, Harris T. Social origins of depression. London: Tavistock Publications, 1978.

16 Solom Z, Bromet $\mathrm{E}$. The role of social factors in affective disorder: an assessment of the vulnerability model of Brown and his colleagues. Psychol Med 1982;12:123-30

17 Corney RH. Health visitors and social workers. Health Visitor 1980;53: $409-13$.

18 Hennessy DA. Should health visitors also care for mothers? In: Hawthorne PJ, ed. Proceedings of the RCN research society annual conference. Nottingham

19 Briscoe ME, Williams P. Emotional problems in the clients of health visitors Health Visitor 1985;58: 197-8.

20 Holden JM. Counselling: instructions to primary care workers. In: Cox JL, ed Postnatal depression: a guide for health professionals. Edinburgh: Churchill Livingstone, 1986

21 Nelson-Jones R. The theory and practice of counselling psychology. London: Holt, Rinehart, and Winston, 1982

22 Goldberg DP, Cooper B, Eastwood MR, Kedward HB, Shepherd M. A standardised psychiatric interview for use in community survevs. Br f Pre Soc Med 1970;24:18-23.

23 Spitzer R, Endicott J, Robins E. Research diagnostic criteria. New York: New York State Psychiatric Institute, 1975. (Instrument No 58 .)

24 Cox JL, Holden JM, Sagovsky R. Detection of postnatal depression development of the Edinburgh postnatal depression scale. Br $\mathcal{F}$ Psychiatry 1987;150:782-6.

25 Frommer EA, O'Shea G. Antenatal identification of women liable to have problems in managing their infants. Brf Psychiatry 1973;123:149-56.

26 Crook T, Elliott J. Parental death during childhood and adult depression: critical review of the literature. Psychol Bull 1980;87:252-9.

27 Paykel ES, Emms EM, Fletcher J, Rassaby ES. Life events and social support in postnatal depression. Brf Psychiatry 1980;136:339-46.

28 Bergin AE, Lambert MJ. The evaluation of therapeutic outcomes. In: Garfield SL, Bergin AE, eds. Handbook of psychotherapy and behavior change. New York: Wiley, 1978:139-89.

Accepted 7 November 1988

\section{ONE HUNDRED YEARS AGO}

A paper by Mr. E. Tidman, on the "Drainage By-laws as Administered under the Metropolis Local Management Acts," recently read before the Association of Public Sanitary Inspectors, comes aptly at a time when London is shortly to be engaged in choosing its future County Councillors. The title of the paper is somewhat of a misnomer, for in the greater portion of the metropolis no drainage by-laws exist or ever have existed. The Metropolitan Board of Works has never exercised the powers conferred on it by Section 202 of the Metropolis Local Management Act to make bylaws for house-drainage, and this section does not enable vestries and district boards to make any for themselves. This omission on the part of the Metropolitan Board of Works has enabled the speculative builder to live and flourish at the expense of the tenants of his wretched jerry-built houses, and was strongly denounced by the Government Commissioners in the Bethnal Green Inquiry as having greatly conduced to the unwholesome condition of houses built since the year 1855. But the vestries and district boards cannot escape from blame on the plea that the drainage of new buildings was solely the business of the Metropolitan Board of Works; there are sections in the Metropolis Local Management Act, 1855- notably 73,75 , and 76 - which enable them to make regulations for the proper drainage of new buildings, which must be carried out to the satisfaction of their surveyor. In how many parishes have such regulations been made and enforced? The Metropolitan Board of Works has never been entrusted with any large supervisory powers over vestries and district boards, but those it had have never been exercised. If the Metropolitan Board had ever taken upon itself the duty of enforcing Torrens's Act at the expense of a defaulting vestry, this Act would not have become the dead letter which in most parishes it now is, and the demolition and reconstruction of slums and rookeries might have proceeded on a scale in some degree approaching modern requirements. We do not wish to press unduly upon a moribund body, except to point the lesson for the new County Council of London, that what the Metropolitan Board of Works has failed to be in the past, the County Council may be in the future. The Metropolitan Board has not existed in vain if the County Council profits by its sins of omission and commission as well as by its good works.

(British Medical Fournal 1889;i:91) 